\title{
Rapid Detection of Mycobacterium tuberculosis in Sputa by the Amplification of IS6110
}

\author{
Toru Hashimoto, Katsuhiro Suzuki, Ryoichi Amitani and Fumiyuki Kuze
}

\begin{abstract}
A polymerase chain reaction (PCR) assay for the rapid detection of Mycobacterium tuberculosis in sputum samples was studied. The target DNA was a 123-base pair (bp) fragment of IS6110, which was repeated in the M.tuberculosis genome and was specific for the M.tuberculosis complex. Glass beads ( $2 \mathrm{~mm}$ diameter) and lysozyme were used to lyse the mycobacteria and DNA was extracted by the phenol-extraction method. The amplified PCR product was detected by examination of ethidium-bromide-stained agarose gel and by hybridization with an oligonucleotide alkaliphosphatase-labeled probe. A total of 70 samples were tested. PCR was positive in all 13 smear and culture-positive samples, in 5 of 8 smear-negative and culture-positive samples, and in 1 of 49 smear and culture negative samples. The overall sensitivity and specificity were $85.7 \%$ and $98 \%$, respectively. Thus, IS6110 as a PCR target was found to be very useful for the rapid diagnosis of M.tuberculosis infection and start of anti-tuberculous chemotherapy.
\end{abstract}

(Internal Medicine 34: 605-610, 1995)

Key words: polymerase chain reaction, insertion sequence, pulmonary tuberculosis

\section{Introduction}

Tuberculosis is once again a disease of increasing importance. Detection of Mycobacterium tuberculosis in clinical specimens is required for the definitive diagnosis of tuberculosis. Microscopic examination requires a relatively large number of bacteria in specimens. Culture confirmation is a sensitive method to detect mycobacteria, however, a period of 4 to 8 weeks is necessary and another 2 to 4 weeks is needed for the final identification of the species by biochemical methods. Therefore, the polymerase chain reaction (PCR) has recently been widely utilized for the detection of M.tuberculosis in clinical samples due to its rapidity and specificity.

Many primers which amplify the specific DNA sequences of M.tuberculosis have been designed and successfully used for the identification of this microorganism (1-7). The sensitivity and specificity of the PCR compared with those of culture methods has been reported to be from 70 to $100 \%$ (6-8). It has been suggested that systems that amplify targets present in multiple copies in the mycobacterial genome could be more sensitive than those that amplify targets present in a single copy (9). The insertion sequence IS6110 is reported to be present multiple times in M.tuberculosis chromosomes (10) and to be specific for M.tuberculosis complex (11). We evaluated a PCR assay which amplifies a specific sequence within IS6110 for its usefulness to detect M.tuberculosis in sputum samples, and compared it to the results of conventional culture on Ogawa egg medium.

\section{Materials and Methods}

\section{Primers and probes}

The primers used for the amplification were originally designed by Eisenach et al from sequences which are repeated 10 to 16 times in the chromosome of M.tuberculosis (12). The sequences of the primers, which amplify a 123-bp fragment of IS6110 were 5'-CCTGCGAGCGTAGGCGTCGG-3' and 5'-CTCGTCCAGCGCCGCTTCGG-3'. And the sequence of oligonucleotide which was used as a probe to identify the amplified DNA in hybridization experiments was 5'TAGCAGACCTCACCTATGTGTCGAC-3'.

\section{DNA extraction from mycobacterial strain and clinical specimens}

The mycobacterial strains that were used are listed in Table 1. The strains were cultured on $1 \%$ Ogawa egg medium at $37^{\circ} \mathrm{C}$. To obtain samples containing a known number of viable bacteria, these strains were then cultured in Dubos Tween albumin

\footnotetext{
From the Department of Infection and Inflammation, First Clinic of Medicine, Chest Disease Research Institute, Kyoto University, Kyoto Received for publication August 31, 1994; Accepted for publication March 20, 1995

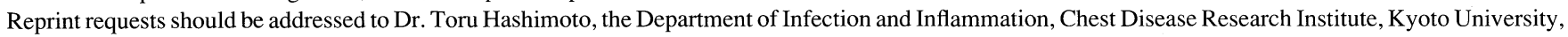
Kyoto 606
} 
Table 1. Stored Mycobacteria Examined in This Study

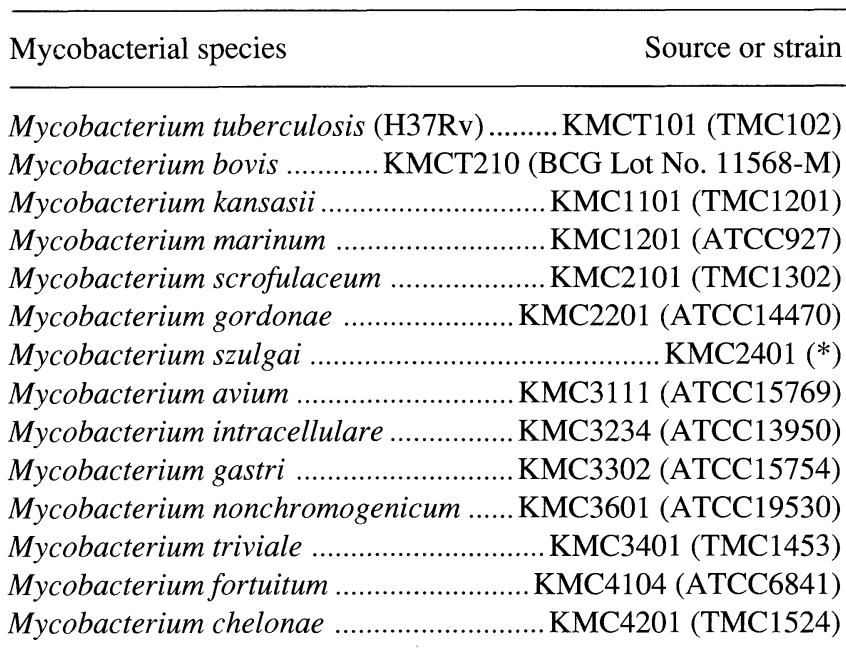

KMC: Kyoto University Mycobacterial Culture Collection, TMC: Trudeau Mycobacterial Culture Collection, ATCC: American Type Culture Collection, * a clinical isolate, originally supplied by Dr. H. Simoide.

liquid medium, and serial 10-fold dilutions of the cultured medium were inoculated onto $1 \%$ Ogawa egg medium to determine the number of colony-forming units (cfu).

Genomic DNA were isolated from cultured mycobacteria with proteinase $\mathrm{K}$ and phenol-chloroform as described previously with slight modification (13). Briefly, the cultured mycobacteria were lysed with $2 \mathrm{~mm}$ diameter glass beads and lysozyme. The specimens were incubated for 2 hours at $37^{\circ} \mathrm{C}$. Then proteins were digested with proteinase $\mathrm{K}$ for 30 minutes at $55^{\circ} \mathrm{C}$ with Tris-EDTA buffer, DNA was extracted with phenol-chloroform-isoamyl alcohol, recovered by ethanol precipitation, and dissolved in distilled water.

\section{PCR procedure}

A reaction mixture of $100 \mu 1$ containing the sample and the primers ( $200 \mathrm{pM}$ each), $1 \times$ Taq polymerase buffer $(50 \mathrm{mMKCl}$, $10 \mathrm{mM}$ Tris [pH 8.8], $1.5 \mathrm{mM} \mathrm{MgCl}_{2}, 0.1 \%$ Triton X-100), 100 $\mu \mathrm{M}$ each of deoxynucleotide triphosphates, was prepared. After the DNA was denatured for 3 minutes at $95^{\circ} \mathrm{C}, \mathrm{Taq}$ polymerase (Wako Pure Chemical Industries; $1.5 \mathrm{U}$ ) was added. Thirty amplification cycles were performed with an automated thermal cycler (PHC-3; Techne Corporation, Cambridge, U.K.). Each cycle consisted of denaturation at $95^{\circ} \mathrm{C}$ for 80 seconds, annealing of primers at $55^{\circ} \mathrm{C}$ for 80 seconds, and primer extension at $72^{\circ} \mathrm{C}$ for 140 seconds. The presence of the 123-bp amplification product was determined by electrophoresis of 10 $\mu 1$ of the amplified mixture on a $0.9 \%$ agarose gel or $3 \%$ Nusieve 3:1 agarose gel (FMC BioProducts, Rockland, U.S.A.). The DNA was stained by ethidium bromide and photographed on a UV transilluminator. Negative and positive controls were included in each amplification experiment.
Table 2. Sputum Samples Examined in This Study

\begin{tabular}{lcc}
\hline Final diagnosis & $\begin{array}{c}\text { No. of } \\
\text { patients }\end{array}$ & $\begin{array}{c}\text { No. of } \\
\text { sputum samples }\end{array}$ \\
\hline Pulmonary tuberculosis & 21 & 33 \\
Lung cancer & 7 & 14 \\
Pulmonary M.avium complex infection & 3 & 4 \\
Bronchiectasis & 3 & 3 \\
Bronchial asthma & 3 & 3 \\
Pulmonary mycosis & 2 & 4 \\
Chronic empyema & 2 & 2 \\
Bronchitis & 1 & 1 \\
Interstitial pneumonia & 1 & 2 \\
Mucoid impaction & 1 & 1 \\
Healed pulmonary tuberculosis & 1 & 1 \\
Pneumothorax & 1 & 2 \\
\hline Total & 46 & 70 \\
\hline
\end{tabular}

\section{Dot blot hybridization}

Five micro liter of the amplified DNA was diluted with $45 \mu \mathrm{l}$ of distilled water and $1 \mu \mathrm{l}$ of the diluted DNA was spotted on a positively charged nylon membrane (Hybond $\mathrm{N}+$, Amersham International plc, Bucks, U.K.). After drying at room temperature, the membrane was placed in $0.6 \mathrm{~N} \mathrm{NaOH}$ for 15 minutes and rinsed in $5 \times$ standard saline citrate (SSC) solution. Hybridization was performed by placing membranes in hybridization solution containing alkaline phosphatase (AP)-labeled probe for 15 minutes at $50^{\circ} \mathrm{C}$. After hybridization, the membrane was washed at $50^{\circ} \mathrm{C}$ in $2 \times \mathrm{SSC}-1 \%$ sodium dodecyl sulfate for 10 minutes and at room temperature in $1 \times$ SSC- $0.5 \%$ Triton X-100 for 10 minutes. To capture the AP activity, the membrane was incubated in a solution of nitroblue tetrazolium chloride substrate, 5-bromo-4-chloro-3-indolyl-phosphate substrate, and AP substrate buffer. After incubation, the hybridization spots on the membrane were observed to detect the presence (positive) or the absence (negative) of a clearly discernible blue or purple color.

\section{Clinical samples}

All sputum samples were obtained from patients in the hospital of the Chest Disease Research Institute. Table 2, lists the final diagnoses.

Each sample was divided into two fractions; one was inoculated onto Ogawa egg medium with routine procedures, and the other was treated with an equal volume of Sputazyme (Kobayashi Pharmaceutical Co.) for 15 minutes at $37^{\circ} \mathrm{C}$. After extracted and precipitated by the previously described method, the DNA was resuspended in $50 \mu \mathrm{l}$ of distilled water and $5 \mu \mathrm{l}$ of the solution was used for the PCR. All samples were analyzed in duplicate. 


\section{Results}

\section{Sensitivity of the PCR}

The sensitivity of the PCR with the primer for IS6110 was determined by adding various amounts of M.tuberculosis (H37Rv) DNA to the reaction vials. The DNA concentration was calculated by using a spectrophotometer (1 optical density at $260 \mathrm{~nm}$ as $50 \mu \mathrm{g} / \mathrm{ml})$. Ten femtogram of the DNA could be amplified sufficiently and reproducibly to give a clearly detectable band in an agarose gel (Fig. 1). The result of the agarose gel electrophoresis was confirmed by dot blot hybridization with the AP-labeled oligonucleotide probe. The detection limit of the DNA by the dot blot hybridization was also found to be 10 femtogram (Fig. 2).

\section{Specificity of the PCR}

DNAs were extracted and purified from 14 mycobacterial species. One nanogram of the purified DNA was used as a target for the PCR. Amplification of the 123-bp fragment was achieved only when DNA from M.tuberculosis or M.Bovis was used. No amplification was observed from DNA of other species of mycobacteria (Fig. 3). The results of the agarose gel

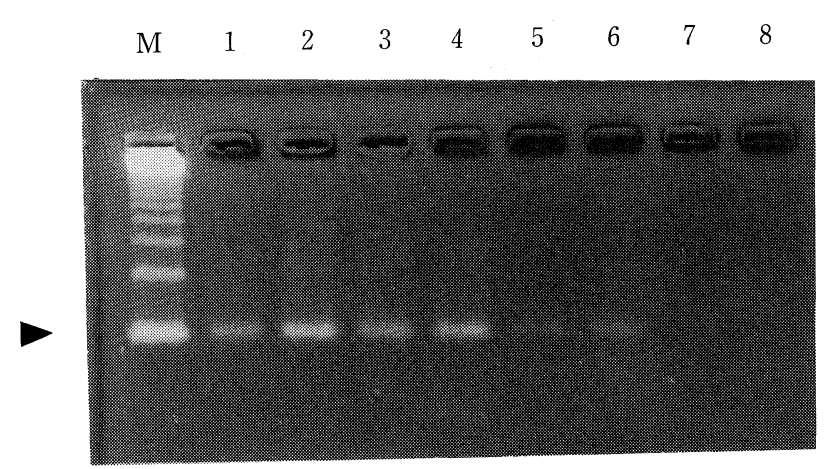

Figure 1. Determination of the sensitivity of the PCR with purified DNA of M.tuberculosis $(\mathrm{H37Rv})$ by agarose gel electrophoresis. M: 123-base-pair DNA ladder marker, lanes 1, 2: 1 pg, lanes 3, 4: $100 \mathrm{fg}$, lanes 5, 6: $10 \mathrm{fg}$, lanes 7, 8: $1 \mathrm{fg}$ of purified M.tuberculosis DNA. Amplification products were detected as a 123-bp band (arrow). Ten femtogram of DNA could be detected by agarose gel electrophoresis.

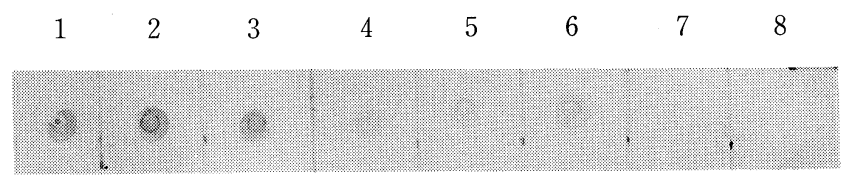

Figure 2. Determination of the sensitivity of the PCR with purified DNA of M.tuberculosis (H37Rv) by dot blot analysis. Lanes 1, 2: 1 pg, lanes 3, 4: 100 fg, lanes 5, 6: 10 fg, lanes 7, 8: 1 fg of purified M.tuberculosis DNA. Ten femtogram of DNA could be detected by dot blot analysis. electrophoresis were confirmed by dot blot hybridization by using the AP-labeled oligonucleotide probe (Fig. 4). The results were also confirmed by Southern-blot hybridization method (data not shown).

\section{Detection of M.tuberculosis after addition to non-tubercu- lous sputum}

Before this method was applied to clinical samples, we examined the sensitivity to detect the bacteria after addition to non-tuberculous sputum. We obtained purulent sputa which contained Pseudomonas aeruginosa from a non-tuberculous bronchiectasis patient. We mixed various cfu of M.tuberculosis $\mathrm{H} 37 \mathrm{Rv}$ strain with this sputum and attempted to amplify the DNA of the strain by the PCR method to determine the detection limit in this sputum condition. In $1 \mathrm{ml}$ of this sputum, 1,000 cfu of the strain was detected, however $100 \mathrm{cfu}$ was undetectable under similar conditions. Therefore, 1,000 cfu was determined

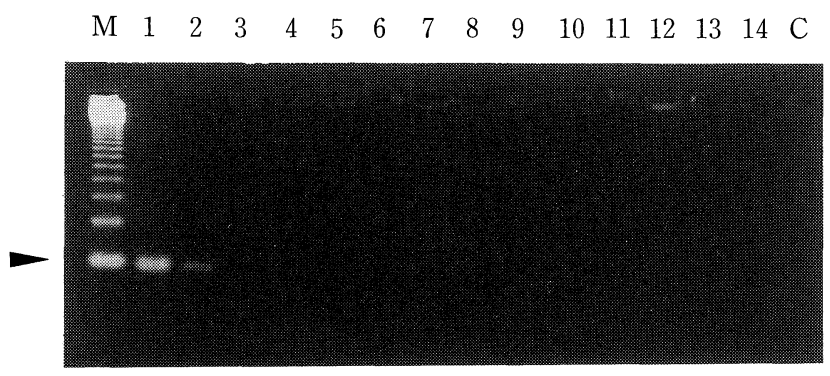

Figure 3. Agarose gel electrophoresis of amplified DNAs of various mycobacterial species. M: 123-base-pair DNA ladder marker, lane 1: M.tuberculosis, lane 2: M.bovis, lane 3: M.kansasii, lane 4: M.marinum, lane 5: M.scrofulaceum, lane 6: M.gordonae, lane 7: M.szulgai, lane 8: M.avium, lane 9: M.intracellulare, lane 10: M.gastri, lane 11: M.nonchromogenicum, lane 12: M.triviale, lane 13: M.fortuitum, lane 14: M.chelonae. Amplification of the 123-bp fragment (arrow) was achieved only when DNA isolated from M.tuberculosis or M.bovis was included as the target DNA. No amplification was observed from DNA of other species of mycobacteria.

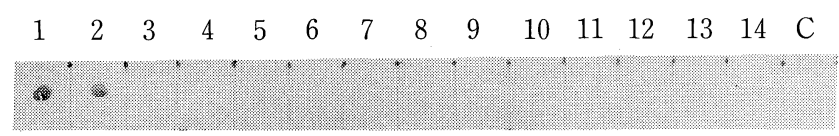

Figure 4. Dot blot analysis of amplified DNAs of various mycobacterial species. Lane 1: M.tuberculosis, lane 2: M.bovis, lane 3: M.kansasii, lane 4: M.marinum, lane 5: M.scrofulaceum, lane 6: M.gordonae, lane 7: M.szulgai, lane 8: M.avium, lane 9: M.intracellulare, lane 10: M.gastri, lane 11: M.nonchromogenicum, lane 12: M.triviale, lane 13: M.fortuitum, lane 14: M.chelonae. Amplification was achieved only when DNA isolated from M.tuberculosis or M.bovis was included as the target DNA. No amplification was observed from DNA of other species of mycobacteria. 
Table 3. Comparison of the Results of Standard Diagnostic Tests and PCR for the Detection of M.tuberculosis in 70 Sputum Samples

\begin{tabular}{lcccc}
\hline $\begin{array}{l}\text { Conventional } \\
\text { method }\end{array}$ & \multicolumn{3}{c}{ Number of samples } \\
\cline { 2 - 5 } & PCR (-) & PCR (+) & Total \\
\hline $\mathrm{S}(-)$ & $\mathrm{C}(-)$ & 48 & 1 & 49 \\
$\mathrm{~S}(-)$ & $\mathrm{C}(+)$ & 3 & 5 & 8 \\
$\mathrm{~S}(+)$ & $\mathrm{C}(+)$ & 0 & 13 & 13 \\
\hline
\end{tabular}

S: acid-fast stain, C: culture, PCR: polymerase chain reaction. Samples were considered PCR positive when the 123-bp fragment was detected in both the agarose gel and dot blot hybridization test. Forty-eight smear, culture, and PCR-negative samples were derived from all 25 nontuberculous patients and 6 patients who were diagnosed as pulmonary tuberculosis based on the clinical considerations on admission. Three culture-positive and PCR-negative samples were derived from 3 patients who were all diagnosed as pulmonary tuberculosis based on the clinical considerations. One culture-negative and PCR-positive sample was derived from a patient who had culturepositive pulmonary tuberculosis and had received antituberculosis drugs for 3 months before sampling.

as the approximate detection limit in the purulent sputum condition.

\section{Detection of M.tuberculosis in clinical specimens}

A total of 70 samples from 46 patients were tested by PCR (Table 2). Samples were considered positive when the 123-bp fragment was detected in both the agarose gel and dot blot hybridization test.

PCR was positive in all 13 smear and culture positive samples, in 5 of 8 smear-negative and culture-positive samples, and in only one of 49 smear and culture negative samples. Therefore, the overall sensitivity and specificity were calculated to be 85.7 and $98 \%$, respectively, based on the culture confirmation (Table 3). Detailed data of 33 samples of 21 tuberculosis patients are shown in Table 4. One patient who was diagnosed as pulmonary tuberculosis because his previous sample was culture positive for M.tuberculosis was included in the pulmonary tuberculosis patients.

Forty-eight smear, culture, and PCR negative samples were derived from all 25 non-tuberculous patients and 6 patients who were diagnosed as pulmonary tuberculosis based on the clinical considerations on admission. Three culture-positive and PCRnegative samples were derived from 3 patients who were all diagnosed as pulmonary tuberculosis based on the clinical considerations on admission. Culture results of the 3 samples were 15,15 , and 7 colonies. One culture-negative and PCRpositive sample was derived from a patient who had culturepositive pulmonary tuberculosis and had received anti-tuberculosis drugs for 3 months before sampling.
Table 4. Detailed Data of the Results of Standard Diagnostic Tests and PCR for 33 Samples of 21 Tuberculosis Patients

\begin{tabular}{|c|c|c|c|c|}
\hline Patient No. & Sample No. & Smear & Culture & PCR \\
\hline \multirow[t]{2}{*}{1} & 1 & 3 & +++ & + \\
\hline & 2 & 3 & +++ & + \\
\hline 2 & 1 & - & - & - \\
\hline \multirow[t]{3}{*}{3} & 1 & - & - & - \\
\hline & 2 & - & - & - \\
\hline & 3 & - & - & - \\
\hline \multirow[t]{3}{*}{4} & 1 & - & - & + \\
\hline & 2 & - & 200 & + \\
\hline & 3 & - & - & - \\
\hline \multirow[t]{6}{*}{5} & 1 & 1 & +++ & + \\
\hline & 2 & 1 & +++ & + \\
\hline & 3 & 1 & ++ & + \\
\hline & 4 & 1 & ++ & + \\
\hline & 5 & 1 & 30 & + \\
\hline & 6 & - & 3 & + \\
\hline 6 & 1 & - & - & - \\
\hline 7 & 1 & - & 15 & - \\
\hline \multirow[t]{2}{*}{8} & 1 & - & - & - \\
\hline & 2 & - & - & - \\
\hline \multirow[t]{2}{*}{9} & 1 & 3 & +++ & + \\
\hline & 2 & 3 & +++ & + \\
\hline 10 & 1 & 3 & +++ & + \\
\hline 11 & 1 & - & 20 & + \\
\hline 12 & 1 & 2 & ++ & + \\
\hline 13 & 1 & - & - & - \\
\hline 14 & 1 & - & - & - \\
\hline 15 & 1 & - & 4 & + \\
\hline 16 & 1 & - & 12 & + \\
\hline 17 & 1 & 1 & ++ & + \\
\hline 18 & 1 & 2 & ++ & + \\
\hline 19 & 1 & - & 7 & - \\
\hline 20 & 1 & - & 15 & - \\
\hline 21 & 1 & - & - & - \\
\hline
\end{tabular}

+++ >500 CFU, ++ 200-500 CFU. Three culture-positive and PCR-negative samples were derived from 3 patients (No. $7,19,20$ ) who were all diagnosed as pulmonary tuberculosis based on the clinical considerations on admission. One culture-negative and PCR-positive sample was derived from a patient (No. 4) who had culture-positive pulmonary tuberculosis and had received anti-tuberculosis drugs for 3 months before sampling. One patient (No. 6) was diagnosed as pulmonary tuberculosis because his previous sample was culture positive for M.tuberculosis.

\section{Discussion}

The potential usefulness of the PCR amplifying IS6110 for rapid diagnosis of pulmonary tuberculosis was investigated. We thought that the repetitive nature of the target sequence in the M.tuberculosis chromosome might contribute to the high sensitivity and stability of the assay. 
One mycobacterium contains approximately $5 \mathrm{fg}$ of DNA and the lower limit of this PCR study was $10 \mathrm{fg}$ of the purified DNA. Therefore, theoretically it is possible to detect 2 mycobacteria in a sample. However, in the case of sputum containing known cfu of M.tuberculosis bacilli, the detection limit was found to be $1,000 \mathrm{cfu}$ in $1 \mathrm{ml}$ of sputum. Thus, the sensitivity of the detection in the sputum preparation was much lower than the pure DNA. We thought that this might be due to loss of the DNA and contamination with Taq polymerase inhibitor such as phenol during the extraction and the purification steps.

In addition, incompleteness of the bacterial lysis during the sample processing could have a significant effect on the lower sensitivity. In fact, a variety of sample preparation methods have been proposed for PCR assays for mycobacteria $(14,15)$. In the comparison of several procedures, we obtained the best results by the glass beads method (data not shown). However, the preparation method should be further studied in order to obtain better sensitivity.

Theoretically, the sensitivity might be enhanced by increasing the number of cycles. Thus, we performed the PCR in 40 cycles, but, the sensitivity was no better than that obtained in 30 cycles. Therefore, the number of cycles was not changed. Other methods that enhance the sensitivity of detection, such as the use of isotopically labeled probes, or reamplification negative samples with nested primers were not employed because such approaches are expensive and are not technically appealing to clinical laboratories.

Clarridge et al have already reported the PCR method for rapid detection of M.tuberculosis in clinical samples with the same target of the present study (16). Their data showed that the overall sensitivity and specificity were 83.5 and $99 \%$, respectively. The present result that showed nearly the same sensitivity of the PCR as the ordinary culture method (Ogawa egg medium) was consistent with their report. In contrast, some reports $(1,4)$ showed the PCR sensitivity to be higher than the culture method. In the case of culture-negative and PCRpositive samples, it is sometimes difficult to differentiate true tuberculosis from contamination and/or non-viable bacilli without meticulous clinical evaluation.

We had 3 culture-positive and PCR-negative samples. Although the culture results of the 3 samples had a relatively low number of colonies (15,15 and 7 colonies), we could detect the bacteria by PCR from samples with lower culture results (the lowest culture result of a PCR positive sample was only 3 colonies). The differing degree of sensitivity might be related to the number of copies of IS6110 in the chromosome of each strain; the number of copies of this insertion sequence can vary from 10 to $16(10)$.

One culture-negative and PCR-positive sample was derived from a patient who had culture-positive pulmonary tuberculosis and had received the treatment for 3 months before sampling. It has been reported that sputum samples can remain PCRpositive for several weeks after initiation of effective treatment because even nonviable organisms can be detected by PCR (13). Other culture-negative samples, which included those from patients who had non-tuberculous mycobacterial infec- tion, were all PCR-negative.

The major problem with PCR methods has been reported to be contamination caused by amplicons, which give a falsepositive result. To prevent this carryover, we separated physically pre- and post-amplification procedures. The negative controls run with each batch of samples failed to identify any contaminating DNA.

Several published reports show the usefulness of PCR in detecting mycobacterial DNA in clinical samples of extrapulmonary tuberculosis, such as pleural effusions or cerebrospinal fluids $(17,18)$. However, we have not attempted analysis of such kinds of samples. It is worth trying to apply the same PCR method to the such samples in the future.

This study demonstrated the utility of PCR for the rapid detection of M.tuberculosis in sputum samples. All the smear and culture positive samples were positive with PCR. Recently, non-tuberculous mycobacterial infections are increasing in Japan (19), it is important to rapidly differentiate $M$.tuberculosis from non-tuberculous mycobacteria in the case of smearpositive samples, which can be done by the PCR within 1 day. Because the PCR method can sometimes show false-negative results, intensive clinical evaluation is still the most important for diagnosis of pulmonary tuberculosis. In addition to the PCR, culture method is also necessary to detect quantitative information and drug resistance.

Acknowledgments: The authors thank Takayuki Ezaki, Professor of Department of Microbiology, Gifu University for his excellent advice.

\section{References}

1) Brisson-Noel A, Gicquel B, Lecossier D, Vincent-Levy-Frebault V, Nassif X, Hance A. Rapid diagnosis of tuberculosis by amplification of mycobacterial DNA in clinical samples. Lancet ii: 1069, 1989.

2) Wit D, Steyn L, Shoemaker S, Sogin M. Direct detection of Mycobacterium tuberculosis in clinical specimens by DNA amplification. J Clin Microbiol 28: 2437, 1990.

3) Sjobring U, Mecklenburg M, Andersen A, Miorner H. Polymerase chain reaction for detection of Mycobacterium tuberculosis. J Clin Microbiol 28: $2200,1990$.

4) Manjunath N, Shankar P, Rajan L, Bhargava A, Saluja S. Evaluation of a polymerase chain reaction for the diagnosis of tuberculosis. Tubercle 72: $21,1991$.

5) Portillo P, Murillo L, Patarroyo M. Amplification of a species-specific DNA fragment of Mycobacterium tuberculosis and its possible use in diagnosis. J Clin Microbiol 29: 2163, 1991.

6) Soini H, Skurnik M, Liippo K, Tala E, Viljanen M. Detection and identification of mycobacteria by amplification of a segment of the gene coding for the 32-kilodalton protein. J Clin Microbiol 30: 2025, 1992.

7) Cousins D, Wilton S, Francis B, Gow B. Use of polymerase chain reaction for rapid diagnosis of tuberculosis. J Clin Microbiol 30: 255, 1992.

8) Pao C, Yen T, You J, Maa J, Fiss E, Chang C. Detection and identification of Mycobacterium tuberculosis by DNA amplification. J Clin Microbiol 28: $1877,1990$.

9) Boddinghause B, Rogall T, Flohr T, et al. Detection and identification of mycobacteria by amplification of rRNA. J Clin Microbiol 28: 1751, 1990.

10) Eisenach K, Crawford J, Bates J. Repetitive sequences as probes for Mycobacterium tuberculosis. J Clin Microbiol 26: 2240, 1988.

11) Thierry D, Brisson-Noel A, Vincent-Levy-Frebault V, Nguyen S, Guesdon J, Gicquel B. Characterization of a Mycobacterium tuberculosis insertion sequence, IS6110, and its application in diagnosis. J Clin Microbiol 28: 2668,1990 . 


\section{HASHIMOTO et al}

12) Eisenach K, Cave M, Bates J, Crawford J. Polymerase chain reaction amplification of a repetitive DNA sequence specific for Mycobacterium tuberculosis. J Infect Dis 161: 977, 1990.

13) Hermans P, Schuitema A, Soolingen D, et al. Specific detection of Mycobacterium tuberculosis complex strains by polymerase chain reaction. J Clin Microbiol 28: 1204, 1990.

14) Folgueira L, Delgado R, Palenque E, Noriega A. Detection of Mycobacterium tuberculosis DNA in clinical samples by using a simple lysis method and polymerase chain reaction. J Clin Microbiol 31: 1019, 1993.

15) Kocagoz T, Yilmaz E, Ozkara S, et al. Detection of Mycobacterium tuberculosis in sputum samples by polymerase chain reaction using a simplified procedure. J Clin Microbiol 31: 1435, 1993.

16) Clarridge J, Shawar R, Shinnick T, Plikaytis B. Large-scale use of polymerase chain reaction for detection of Mycobacterium tuberculosis in a routine mycobacteriology laboratory. J Clin Microbiol 31: 2049, 1993.

17) Shankar $P$, Manjunath $N$, Mohan $K$, et al. Rapid diagnosis of tuberculosis meningitis by polymerase chain reaction. Lancet 337: 5, 1991.

18) Lassence A, Lecossier D, Pierre C, Cadranel J, Stern M, Hance A. Detection of mycobacterial DNA in pleural fluid from patients with tuberculous pleurisy by means of the polymerase chain reaction: comparison of two protocols. Thorax 47: 265, 1992.

19) Tsukamura $M$, Kita N, Shimoide $H$, et al. Studies on the nontuberculous lung mycobacteriosis in Japan. Kekkaku 63: 493, 1988 (Abstract in English). 